\title{
Metascience
}

Book review of Paula Stephan "How Economics Shapes Science" (2012), Cambridge (MA) and London: Harvard University Press, 305pp. + references and index.

\section{Blinded by (Economic) Science}

\section{David Tyfield, Lancaster University}

Paula Stephan is an erudite scholar of the economics of science, and her years of expertise and research are skilfully distilled in this interesting book. Over 10 readable and information-packed chapters, she pulls together a comprehensive picture of "what economics has to do with science" and, vice versa, "how science affects the economy" (p.xi), focusing explicitly on the case she knows best and which is of greatest global significance, namely the United States. In doing so, she also explicitly adopts definitions of the two elements of the 'economics of science' as, respectively: a mainstream economics concerned with "study of incentives and costs, of how scarce resources are allocated across competing wants and needs" (p.1); and the (publicly-funded) research done by universities and research institutions in the natural sciences and engineering. Stephan's focus is thus on issues such as how much is spent on this science, in what ways, how economics itself can illuminate the incentive mechanisms that underpin the scientific enterprise and its production of knowledge, the 'value for money' of this public funding given the contribution of that science in turn to economic growth and the efficiency of its actual distribution.

While presented as the common-sense understanding of the 'economics of science', this is not by any means the only way this important concern has been interpreted (see below). Nonetheless, she is surely right that this interpretation of the question is the dominant one today, as both its most obvious disciplinary formulation and that which would be accorded the greatest scientific authority. And in taking on this task, this book is about as strong a summary of this literature as one could hope to find. Across the range of issues discussed from explaining the fundamental economic incentives of the priority system, which enables competition to publish first between scientists on the basis of permanent personal association with a finding, to the economic patterns of scientific knowledge production - the book deftly and succinctly summarizes large literatures, mobilizing impressive detail and a persuasive rigour.

Important also are the numerous cogent criticisms of this current (American) system of 'science' that these discussions evince. Indeed, it is when making these arguments, and making them so carefully, that the book surely has the most interest for most readers, wading into arenas of considerable controversy and debate.

For instance, Stephan lays out the systematic oversupply of $\mathrm{PhD}$-qualified scientists, noting the "disparity between aspirations of young scientists and engineers and the reality that... at most $25 \%$ will get a permanent position in academia" (p.170), the rest "likely to play supporting roles [in their research careers] for life" (p. 81). This is thus to expose how modern 'science' - dominated by the American model, but by no means only in that country - is effectively built upon a false prospectus, an open secret that systematically empowers those already with senior, permanent posts to dangle before ambitious young scientists.

Similarly, she notes "worrisome threats to open science" (p.118) from a growing trend of exclusive research alliances between university labs and private sector R\&D-intensive firms, 
such as Novartis-University of California Berkeley or Merck-MIT. And she describes at length the myriad problems from different forms of funding, such as inefficiencies from reduplication, downplaying of the importance of collaboration or the twisting of incentives to favour risk-averse research agendas that are effectively guaranteed successful results... in order then to get the next grant in turn. Regarding this latter point, she notes how this system of privileging the successful track record when awarding further grants not only creates a 'Matthew Effect' of self-fulfilling concentration of funding that may initially be a matter of luck not 'talent'. But it also threatens to subvert the most fundamental characteristic of scientific research; namely, that the result is not known in advance, hence the need to experiment to find out. Here, then, 'science' is apparently being slowly killed through the creeping growth instead of grant-chasing 'research'.

Strengthening these criticisms, though, is her balanced presentation of findings that do not corroborate with a wholesale critique of recent shifts towards marketization of this public science. For instance, she notes that, against concerns that patenting may undermine publishing of results, in fact for individual scientists higher rates of patenting correlate with higher rates of publication. Yet, she notes, this "does not mean patenting does not impede research" (p.58). This is just the kind of careful analys is that can too easily get lost in broader debates about these issues, overwhelmed by ex ante political positioning, and she shows just how much can be achieved by cleaving strictly to the actual evidence.

But, ironically, this approach also unwittingly reveals its profound limitations and those of the 'economics of science' more broadly, thus conceived. First, if possibly a minor point, it paints a picture of the scientific enterprise, especially in its current manifestation in the US surely the biggest system of scientific research in history - that is not merely problematic and in (urgent) need of attention and improvement, but rather one that is almost essentially unattractive and depressing, cut-throat and money-grabbing, self-preserving and/or insecure; truly a 'dismal' world illuminated by the dismal science. To be sure, all these characteristics are unquestionably features of modern science and scientists. But from this portrayal it is hard to see why science is a realm of human activity worth fighting for or devoting one's working life to.

Secondly, from chapter to chapter and especially regarding the all-important discussion of the evidence of whether and how science contributes to economic growth (chapter 9), the overwhelming conclusion of Stephan's masterful summary is the sheer extent of our ignorance and, worse, the simple unanswerability of many of the key questions that thus framing would pose. Not only do we not really know how science contributes to economic growth - or, pace Stephan's assertion that it is "beyond doubt" (p.215), whether it does so (Edgerton 2017) - but the kinds of more detailed questions and research that could flesh out our understanding are often impossible to address, whether for pragmatic or conceptual reasons.

For instance, while historical analysis can reconstruct the essential contribution of specific lines of research to particular innovations in qualitative terms, how can quantitative measures of the broader contribution of all scientific research to all technical change be constructed? This would have to include all the research that has led nowhere, at least for the time being; which simply, in turn, raises the objection of how many years in the past to draw the line. And why should only positive contributions to economic growth be counted? Why discount the possibility that various lines of research actively undermine economic growth, not just through their direct opportunity costs but through enabling distinctively sub-optimal 
innovation trajectories? Such complexity, counterfactuals and challenges of data render these essential questions irredeemably moot.

As such, though, this suggests not only that these are difficult questions - crying out for 'more research', in a parody of the games and ratchets of lobbying for research funding that Stephan herself lucidly describes - but rather the wrong questions. In other words, perhaps a different framing of these issues of the funding of science, its economic aspects and its economic impact could offer more tractable questions, and more compelling insights. This would certainly be this reviewer's approach, pointing to the growing literature on the political economy - and even cultural political economy - of science. For this heterodox and wideranging scholarship brings into focus multiple issues that are both unarguably central to the contemporary 'economics of science' and yet strikingly absent in Stephan's account.

These issues would include a fundamental concern with the qualitative effects on 'science' of the specific economic models currently dominating its pursuit. This approach notes how the very meaning and substance of 'science' as a social phenomenon is dynamically co-produced with changes in the broader economy and society, not a set and fixed entity, as it is by definition in Stephan's mainstream 'economics of science'. Similarly, this approach would not start by presuming that 'science' is, or even can be, best conceptualized as the research done by public research institutes and universities. To the contrary, if we expand our purview and acknowledge how science and political economy co-evolve we are forced to acknowledge how the vastly greater part of science actually takes place in corporate and industrial settings. As Edgerton (2017) notes, quoting the classic study of Rose \& Rose (1976), without this recognition of how science is much more than academic research "the fundamental character of science \& technology is lost to sight." Yet it is precisely these bigger issues and questions that primarily shape an interest in the 'economics of science' and its findings and analyses.

For instance, as this book exemplifies, absent these issues it is all too easy to miss how significantly the science-economy relation has changed in recent years and to underplay the deep dysfunctions it has instituted. Crucial, here, for example, is the whole issue of debt both of higher education institutions and students - which merits not a single mention in the whole book, even as US student debt stands today at $\$ 1.4$ trillion, with a default rate of nearly $20 \%$, making it a fundamental risk to the US (and so global) economy that potentially surpasses the sub-prime bubble of 2007 (Foroohar 2017).

Finally, but by no means last, while Stephan repeatedly makes cogent points regarding the manifest systemic dysfunction of the current economic arrangements of science - albeit in her measured, understated way - and stresses, with Kenneth Arrow, that "society is more ingenious than the market" (p.7,111), the mainstream economics of science that she is purveying is not, and cannot be, the politically innocent and neutral 'scientific' enterprise that the books argues for and presents itself to be. I am reluctant to labour this point, as it has been made so powerfully already by others, notably Mirowski (2011). But the whole framing of the 'economics of science' in terms of such mainstream economics has, in fact, been a major protagonist in the profound, and negative, transformation of the broader scientific enterprise over the past 40 years and beyond.

In other words, instead of attempting to provide a convincing account for why such public science should be funded by answering the impossible questions of this 'economics of science' in terms of providing evidence of the measured contribution of 'science' to 
economic growth, far better to address these decisions as what they are: political economic choices that can still draw on rationales and compelling analysis and evidence but just not from mainstream economics. This could be, for instance, Collini's (2012) humanistic analysis of the essential contribution of public funding for science (and the humanities) in order to cultivate thoughtful, imaginative, critical citizens. Or perhaps more novel, timely arguments regarding the societal need to produce the knowledge and knowledge-adept people for a thriving society beset by the challenges of post-human technological redundancy, acceleration of socio-technical change, government of complex systems and the imminent breaching of planetary boundaries. Sadly, for all its scientific rigour and interesting detail, the 'economics of science' presented by this book simply stands in the way of asking, or even seeing, these broader urgent questions.

David Tyfield is author of 'The Economics of Science' (2 volumes, Routledge 2012) and coeditor of the 'Routledge Handbook of the Political Economy of Science' (Routledge, 2017 forthcoming).

\section{References}

Collini, S. (2012) What are Universities For?, London: Penguin.

Edgerton, D. (2017) 'The political economy of science: prospects and retrospects', in D. Tyfield, R. Lave, S. Randalls and C. Thorpe (eds), The Routledge Handbook of the Political Economy of Science, London \& New York: Routledge.

Foroohar, R. (2017) 'Dangers of the college debt bubble', Financial Times, $10^{\text {th }}$ April.

Mirowski, P. (2011) Science-Mart: Privatizing American Science, Cambridge, MA: Harvard University Press.

Rose, H. and S. Rose (eds) (1976) The Political Economy of Science: Ideology of/in the Natural Sciences, London: Macmillan. 